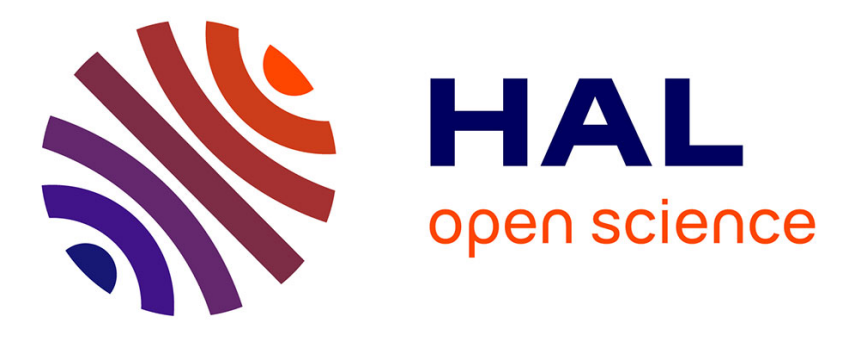

\title{
Laser damage growth with picosecond pulses
}

\author{
Martin Sozet, Jérôme Neauport, Eric Lavastre, Nadja Roquin, Laurent
}

Gallais, Laurent Lamaignère

\section{To cite this version:}

Martin Sozet, Jérôme Neauport, Eric Lavastre, Nadja Roquin, Laurent Gallais, et al.. Laser damage growth with picosecond pulses. Optics Letters, 2016, 41 (10), pp.2342 - 2345. 10.1364/OL.41.002342 . cea-01623412

\section{HAL Id: cea-01623412 https://hal-cea.archives-ouvertes.fr/cea-01623412}

Submitted on 25 Oct 2017

HAL is a multi-disciplinary open access archive for the deposit and dissemination of scientific research documents, whether they are published or not. The documents may come from teaching and research institutions in France or abroad, or from public or private research centers.
L'archive ouverte pluridisciplinaire HAL, est destinée au dépôt et à la diffusion de documents scientifiques de niveau recherche, publiés ou non, émanant des établissements d'enseignement et de recherche français ou étrangers, des laboratoires publics ou privés. 


\title{
Laser damage growth with picosecond pulses
}

\author{
Martin Sozet, ${ }^{1,2, \star}$ Jérôme Neauport, ${ }^{1}$ Eric Lavastre, ${ }^{1}$ Nadja Roquin, ${ }^{1}$ Laurent Gallais, ${ }^{2}$ and \\ LAURENT LAMAIGNÈRE ${ }^{1}$ \\ ${ }^{1}$ CEA, CESTA, F-33116 Le Barp, France \\ ${ }^{2}$ Aix-Marseille Université, CNRS, Centrale Marseille, Institut Fresnel UMR 7249, 13013 Marseille, France \\ ${ }^{*}$ Corresponding author: martin.sozet@cea.fr
}

Received 4 March 2016; revised 20 April 2016; accepted 21 April 2016; posted 22 April 2016 (Doc. ID 260540); published 11 May 2016

\begin{abstract}
Laser-induced damage growth has been investigated in the subpicosecond regime at $1030 \mathrm{~nm}$. We have herein studied the growth of damage sites initiated on a high-reflective dielectric coating under subsequent laser irradiations at a constant fluence. We show through an experimental approach that growth can be triggered for fluences as low as $50 \%$ of the intrinsic damage threshold of the mirror. Moreover, once growth starts, damage areas increase linearly with the number of laser shots. The behavior of defect-induced damage sites has been observed more extensively, and it appears that their growth probability depends on their initiation fluence. () 2016 Optical Society of America
\end{abstract}

OCIS codes: (140.3330) Laser damage; (140.7090) Ultrafast lasers; (310.0310) Thin films.

http://dx.doi.org/10.1364/OL.41.002342

Operation of laser systems is often limited by the optics lifetime. Under high fluences, damage may occur on optics and can impact laser performances as well as induce damage on downstream optical components. In this context, many studies have been carried out to better understand laser damage resistance of optical components. In the case of subpicosecond laser systems, the effect of irradiation conditions (fluence, pulse duration, wavelength, number of pulses, and environment) [1-4], design and manufacturing conditions (coating process, materials, electric-field distribution) [5,6] were thoroughly studied. Overall, it has been demonstrated that the laser damage resistance of an optic in the subpicosecond regime is both limited by its intrinsic properties (linked to its electronic structure) [7,8] and by the presence of embedded defects induced by the manufacturing process $[4,9]$. The densities of such embedded defects can be as high as two hundreds of defects $/ \mathrm{cm}^{2}$, estimated from the measurement of damage densities during rasterscan tests [10]. The questions we wanted to answer in this Letter are: Once a damage site is initiated, what is its growth probability? How do damage sites evolve after subsequent laser pulses in the subpicosecond regime? When growth occurs, the obscuration level of an optic can make the component unusable. Additionally, wavefront modulations due to large damage sites can impact the rest of the downstream laser line. This issue has been deeply investigated in the nanosecond regime. Norton et al. have studied damage growth behavior on fused silica [11] and have reported a shot-to-shot linear growth of diameters when damage is located on the input surface and an exponential growth when the damage site is on the exit surface. A probabilistic approach of damage growth on the exit surface of silica has also been explored $[12,13]$. It reveals that the growth probability strongly depends on the initial damage site, and that its evolution as a function of growth fluences fits a sigmoid trend. Few experiments have been conducted on high-reflective (HR) dielectric coatings in the nanosecond regime [14], and have shown a linear growth of damage diameters. More recently, damage growth sequences on a HR coating at 30-ps have been observed [15]. They report an increase in damage diameter of $\sim 20-30 \mu \mathrm{m} / 50$-shots at fluences $\sim 5.5-7.5 \mathrm{~J} / \mathrm{cm}^{2}$. In order to get a better knowledge of growth behavior under subsequent subpicosecond laser shots, growth experiments have been carried out on a dielectric mirror for different damage sites (intrinsic or defect-induced damage). A common growth behavior has been exhibited for all damage sites in this mirror. Growth probabilities as well as growth rates have been measured and parameterized as a function of growth fluences.

Laser damage experiments are carried out with the setup described in [8]. The wavelength during this experimental study is $1030 \mathrm{~nm}$. A sech ${ }^{2}$ fit of the autocorrelation trace measured with a single-shot autocorrelator gives an estimation of the pulse duration of $980 \mathrm{fs} \pm 20 \mathrm{fs}$. The laser beam is Gaussian-shaped and focuses by means of a $150 \mathrm{~mm}$-focus lens. The beam diameter in the focal plan and the corresponding area are, respectively, $65 \mu \mathrm{m}$ and $3350 \mu \mathrm{m}^{2}$ at $1 / \mathrm{e}$ at normal incidence. The fluence $F$ of a laser shot is reported in terms of normal beam fluence. According to the ISO standard [16], it corresponds to the energy density at the top of the Gaussian beam. $F$ is calculated as the ratio of the total energy in the beam to the effective beam area (set as the area at 1/e for a Gaussian beam). The tested sample is a $\mathrm{HfO}_{2} / \mathrm{SiO}_{2} \mathrm{HR}$ coating \{design: [Glass: $(\mathrm{HL})^{\wedge} 17 \mathrm{H}$ 2L: Air]\} manufactured with an e-beam process and optimized for 1053-nm, $45^{\circ}$ incidence, p-polarization. The bandwidth of this mirror $(\simeq 100-\mathrm{nm})$ is sufficiently broad to maintain the HR property at $1030-\mathrm{nm}$. Moreover, the modification of the $E$-field induced by the use of a 1030 -nm wavelength is weak with respect to $1053-\mathrm{nm}$. A difference of the $E$-field enhancement lower than $5 \%$ is calculated. Measurements are conducted at its operating incidence and polarization, in air. 
A 1/1 test has been performed to assess the laser-induced damage threshold (LIDT) of this mirror [16]. The fluence threshold $F_{\text {th }}$ is $4.00 \pm 0.05 \mathrm{~J} / \mathrm{cm}^{2}$ [17]. For fluences higher than $F_{\text {th }}$, damage is triggered intrinsically to the material with only one irradiation. On the other hand, for lower fluences, the incubation effect can lead to the formation of damage when a pristine site is irradiated with multiple pulses [3]. Rasterscan experiments have also been done on the mirror to reveal the presence of embedded defects such as nodules [10]. It can be suggested that the initial damage can have an impact on growth behavior. We therefore performed growth experiments on damage sites triggered on defects embedded in the coating and on the pristine material itself. Overall, three configurations were considered:

- Initial sites correspond to defect-induced damage sites (DDS). A rasterscan test has been performed on a centimeter square area at a fluence set at $90 \%$ of the $1 / 1$ LIDT. Damage sites due to the ejection of defects embedded in the HR coating have been triggered. A damage density of $48 \mathrm{dam} / \mathrm{cm}^{2}$ has been measured. Growth experiments on DDS have been performed at several fluences $F$, chosen between $40 \%$ of $F_{\text {th }}$ and $90 \%$ of $F_{\text {th }}$. It is reduced to the notation $F \in\left[0.4 F_{\text {th }}, 0.9 F_{\text {th }}\right]$. An example of the initial morphology is reported in Fig. 1(a), picture labeled \#0 (top left corner).

- Initial sites are intrinsic damage sites (IDS) obtained with one irradiation at a fluence higher than $F_{\text {th }}$. Their typical morphology is shown on Fig. 1(b), labeled \#0, and exhibits a delamination of the top layer. Growth experiments on IDS have been performed at $F \in\left[0.4 F_{\text {th }}, 0.7 F_{\text {th }}\right]$.

- Initial sites are pristine and defect-free sites (PS). For each site, several pulses are fired at a set fluence $F \in\left[0.9 F_{\text {th }}, 1.1 F_{\text {th }}\right]$.

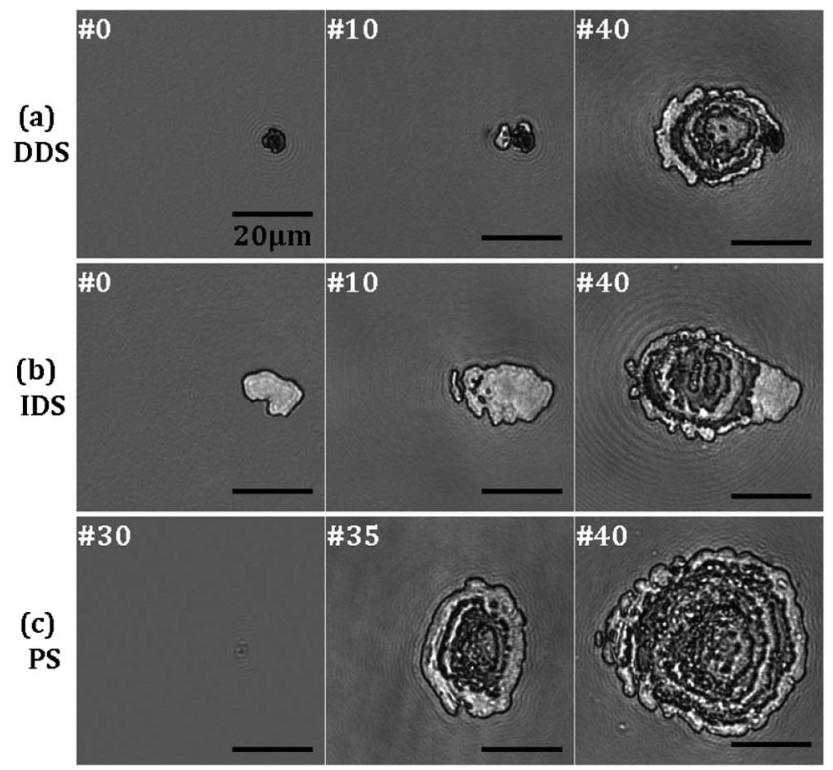

Fig. 1. Microscopic observations perpendicular to the surface of damage sites during growth sequences: Sites are tested at $45^{\circ}$ incidence. On micrographs, the laser beam comes from the right. Each row represents the evolution of the same site after a number of laser irradiations indicated in the top left corner of the image. Initial sites (shot $\# 0$ ) are (a) DDS; (b) IDS obtained at $4.37 \mathrm{~J} / \mathrm{cm}^{2}$. For (c) PS, we give the onset of damage, which occurs at shot \#30. The mean fluence values during growth sequences are, respectively, (a) $2.35 \mathrm{~J} / \mathrm{cm}^{2}$; (b) $2.39 \mathrm{~J} / \mathrm{cm}^{2}$; and (c) $3.91 \mathrm{~J} / \mathrm{cm}^{2}$. See Visualization 1 for complete growth sequences.
Once damage is triggered, the sequence is maintained at the same fluence to assess the growth of the damage area.

The following results have been obtained by testing more than 20 sites for each configuration. We first focus on growing sites. Initial sites are observed at normal incidence, from the front side of the sample with an in-line microscope, which used a $50 \times$ objective operating in transmission. Illumination from the back side of the sample is done with a 515-nm light. Sites are positioned on the point of impact of the beam by means of motorized stages. During the growth sequence, the damage area is observed before and after each pulse. Examples of damage site evolution during growth are shown in Fig. 1 for the three above-mentioned configurations. Complete growth sequences are given in Visualization 1. Each row corresponds to a unique site followed during its growth sequence. A label on the top of the picture indicates the number of pulses that have irradiated the site.

In total, 50 growing sites have been analyzed. Image processing of the growth sequences was performed using ImageJ software [18]. By this means, the damage area was measured for each pulse. An IDS area evolution [site illustrated in Fig. 1(b)] as a function of the number of irradiations is reported in Fig. 2. The first main information given by this graph is that the damage area has grown linearly during tens of laser irradiations. The same linear growth trend has been observed on all DDS, IDS, and PS once growth started. Thus, the second piece of information provided by these experiments is that the growth behavior has been the same whatever the origin of the initial damage. For all three damage sites, damage structure results in the removal of dielectric layers. The formation of a hole in the coating strongly modifies the distribution of the $E$-field in the mirror [19]. It has been observed that damage location can be related to a strong $E$-field enhancement [6]. Thus, shot-to-shot changes in damage morphology modify the $E$-field enhancement in the dielectric layers, thus sustaining the damage growth.

We suggest that during the linear phase the damage area evolves as

$$
S_{n}=\alpha \times n+S_{0},
$$

$S_{0}$ and $S_{n}$ being, respectively, the initial damage area and the damage area after $n$ laser pulses. $\alpha$ in Eq. (1) is set as the linear

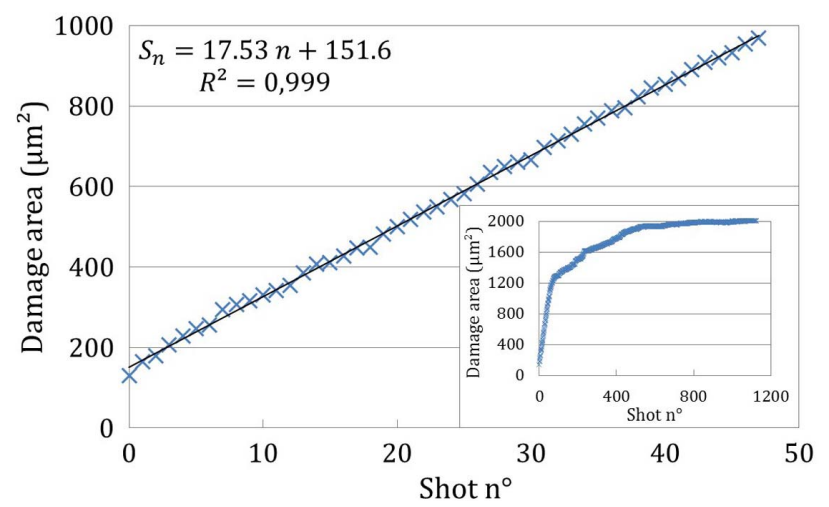

Fig. 2. Evolution of the damage area of the site shown in Fig. 1(b). The graph illustrates the linear growth of the damage area at the beginning of the growth sequence. A linear fit to the data is also reported with the $R$-squared value for this fit. In the insert, the complete growth sequence is reported. The linear evolution is followed by a saturation in growth, related to the beam size. 
growth coefficient. In Fig. 2, linear fit to the data for this phase gives a $R$-squared of 0.999 . $R$-squared values higher than 0.99 have also been measured for all 50 growing sites, which is consistent with the linear trend assumption.

The linear phase is followed by a saturation in growth, as shown with the insert in Fig. 2. We relate the saturation effect to the spatial Gaussian shape and the beam size, as explained for growth experiments with small laser beams in the nanosecond regime [13]. During growth sequences, irradiations are centered on the initial damage location. Since then, the edge of the damage site was irradiated with a local fluence that decreased while damage grew, reaching a local fluence too low to maintain growth. We rather focus on the linear part of the growth sequence. As shown in Fig. 2, the linear growth phase is extracted from the whole growth sequence. Criteria for the extraction consist in selecting the longest phase, which provides a $R$-squared value $>0.99$ when fitted with a linear curve. The $\alpha$ coefficient has been measured for different growth fluences. Results are reported in Fig. 3 and evidence suggests that the growth coefficient increases with the fluence. Moreover, while considering DDS and IDS (square points and triangle points in Fig. 3), no growth occurs for fluences lower than $50 \%$ of the $1 / 1$ LIDT.

The second part of this Letter deals with growth probabilities of DDS. 1/1 and S/1 LIDT of defect-free optics can be accurately assessed in the subpicosecond regime, since damage has a strong nonlinear dependence on intensity [1]. Thus, they can operate at fluences where damage intrinsic to the materials can be avoided. However, damage due to embedded defects does not follow the same deterministic behavior [10], and once triggered, their growth probability is of main concern. Three areas were rasterscanned at $30 \%, 70 \%$, and $90 \%$ of the 1/1 LIDT. On all three areas, DDS densities are, respectively, $31 \mathrm{dam} / \mathrm{cm}^{2}, 48 \mathrm{dam} / \mathrm{cm}^{2}$, and $48 \mathrm{dam} / \mathrm{cm}^{2}$. On each damage site, a hundred laser shots are fired at a constant fluence. If no growth occurs, the fluence is increased, and a new set of shots is fired. If growth occurs, the ramp is stopped. Ramps are applied from fluences lower than $20 \%$ of the $1 / 1$ LIDT to fluences higher than $80 \%$ of the $1 / 1$ LIDT. For all three sets of initial damage sites, tested fluences and the corresponding growth probabilities are given in Fig. 4. A recent study [15] reports a possible conditioning effect when ramps of fluence are applied on a site. This effect is of main concern for the high-power laser community and must be the topic of future

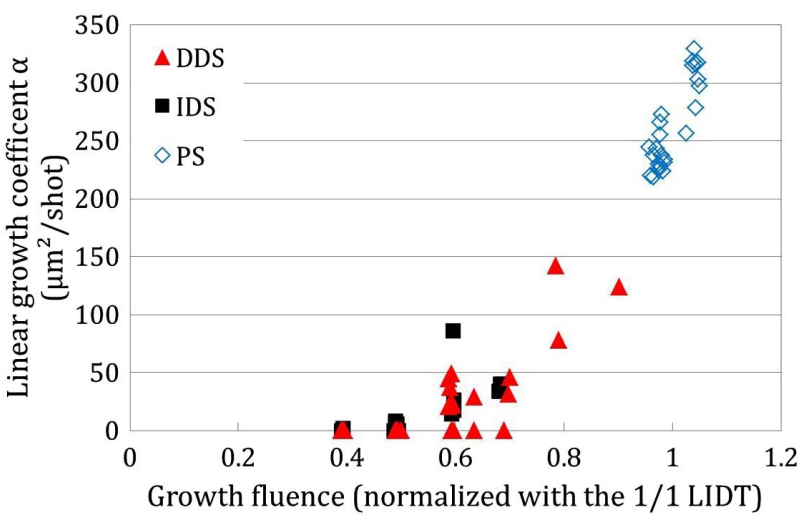

Fig. 3. Evolution of the linear growth coefficient $\alpha$ as a function of the fluence chosen during the growth sequence.

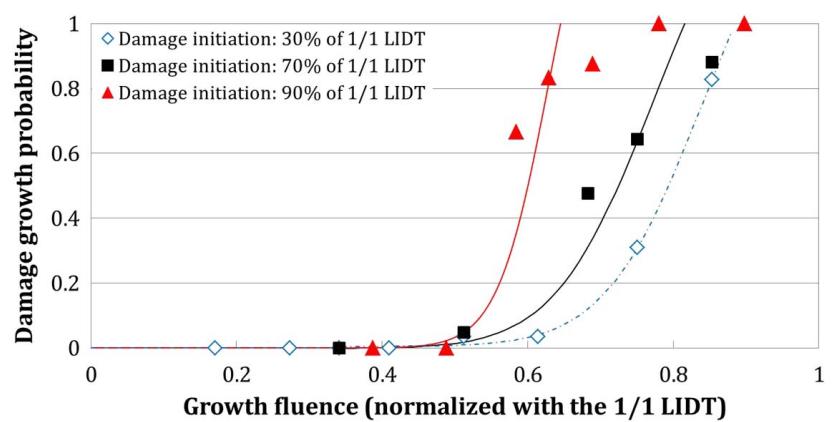

Fig. 4. Evolution of the probability of growth of DDS as a function of fluence (normalized with respect to the 1/1 LIDT). Curves are guides for the eye.

work. However, possible conditioning effects have not been taken into account in our experiments.

As shown in Fig. 4., for a same growth fluence, the higher the fluence of initiation, the higher the growth probability. Gallais et al. studied nodular defects in HR coatings and noticed that the morphology of defect-induced damage changes with the fluence of irradiation [9]: For high fluences, damage is characterized by the removal of several layers, whereas for low fluences, nodules are ejected without extended damage. Thus, the enhancement of the $E$-Field in the interferential coating for subsequent pulse will be totally different. It can explain the difference in growth probabilities among the three sets of damage sites. The second piece of information, illustrated by Fig. 4, is that a fluence higher than $50 \%$ of the $1 / 1$ LIDT is necessary to trigger growth on this mirror, whatever the initial defectinduced damage. It is consistent with the values of the growth coefficient, which tend to zero when the fluence of growth is getting closer to $50 \%$ of the $1 / 1$ LIDT, as presented in Fig. 3. A similar behavior for another $\mathrm{HfO}_{2} / \mathrm{SiO}_{2} \mathrm{HR}$ mirror with engineered nodules embedded in the coating have been found [9]: A growth probability equal to zero stood out in both cases for fluences of growth around $50 \%$ of the $1 / 1$ LIDT.

In conclusion, we have shown that a fluence lower than the LIDT of the defect-free optic exists for which damage growth phenomenon is triggered. For our sample, this fluence has been set at $50 \%$ of the $1 / 1$ LIDT. From then on, the probability of growth differs from zero and increases with the fluence. Once initiated, damage areas tend to grow linearly with the number of subsequent irradiations, whatever the origin of the initial damage. The growth coefficient increases with the fluence that is set during growth sequences. The knowledge of the evolution of the damage area after several irradiations must be used to predict the lifetime of optics in laser facilities and must help to keep the system functional. In the present study, a small Gaussian beam is used. High-power laser facilities commonly use meter scale size flat top beams. Thus, the effect of the beam size is of main concern. In the nanosecond regime, similar behavior in growth with small and large beams has been observed [20]. To investigate this field in the short pulse regime, a setup using a larger beam with a square top-hat spatial profile is under development. Growth experiments with different beam sizes will be conducted on the same mirror to compare the influence of the spatial profile on the growth behavior. The steep edges of the top-hat profile will be of great interest in studying the saturation effect. Another main conclusion of this 
work is that even if $1 / 1$ or S/1 LIDT measurements, as widely used in the community, are useful for the design of the manufacturing optimization of optical components, the study of DDS and their growth is a relevant metrology. Recently, the planarization of nodular defects has highly improved the damage resistance of HR coatings in the nanosecond regime [21]. Such technologies might be of great interest in the subpicosecond regime to reduce the ejection of deeply embedded defects and, as a logical consequence, DDS growth. Numerical simulations are under way to predict the evolution of damage sites with subsequent pulses as a function of the fluence that irradiates the dielectric mirror and the initial damage site. They are based on the evolution of the $E$-field distribution in the interferential coating that is modified, since damage morphology changes.

Funding. Conseil Régional d'Aquitaine through ENDOPICO project (20 131603 005).

\section{REFERENCES}

1. B. C. Stuart, M. D. Feit, S. Herman, A. M. Rubenchik, B. W. Shore, and M. D. Perry, Phys. Rev. B 53, 1749 (1996).

2. D.-B. Douti, L. Gallais, and M. Commandré, Opt. Eng. 53, 122509 (2014).

3. M. Mero, B. Clapp, J. C. Jasapara, W. Rudolph, D. Ristau, K. Starke, J. Krüger, S. Martin, and W. Kautek, Opt. Eng. 44, 051107 (2005).

4. D. A. Alessi, C. W. Carr, R. P. Hackel, R. A. Negres, K. Stanion, J. E. Fair, D. A. Cross, J. Nissen, R. Luthi, G. Guss, J. A. Britten, W. H. Gourdin, and C. Haefner, Opt. Express 23, 15532 (2015).

5. C. J. Stolz and F. Y. Génin, Optical Interference Coatings, N. Kaiser and H. K. Puker, eds. (Springer, 2003), pp. 309-333.
6. J. Neauport, E. Lavastre, G. Razé, G. Dupuy, N. Bonod, M. Balas, G. de Villele, J. Flamand, S. Kaladgew, and F. Desserouer, Opt. Express 15, 12508 (2007).

7. M. Mero, J. Liu, W. Rudolph, D. Ristau, and K. Starke, Phys. Rev. B 71, 115109 (2005).

8. B. Mangote, L. Gallais, M. Zerrad, F. Lemarchand, L. H. Gao, M. Commandré, and M. Lequime, Rev. Sci. Instrum. 83, 013109 (2012).

9. L. Gallais, X. Cheng, and Z. Wang, Opt. Lett. 39, 1545 (2014).

10. M. Sozet, J. Neauport, E. Lavastre, N. Roquin, L. Gallais, and L. Lamaignère, Opt. Lett. 40, 2091 (2015).

11. M. A. Norton, E. E. Donohue, M. D. Feit, R. P. Hackel, W. G. Hollingsworth, A. M. Rubenchik, and M. L. Spaeth, Proc. SPIE 6403, 64030L (2007).

12. R. A. Negres, G. M. Abdulla, D. A. Cross, Z. M. Liao, and C. W. Carr, Opt. Express 20, 13030 (2012).

13. M. Chambonneau, M. Chanal, S. Reyné, G. Duchateau, J.-Y. Natoli, and L. Lamaignère, Appl. Opt. 54, 1463 (2015).

14. J. Taniguchi, N. E. LeBanon, J. Howe, D. J. Smith, C. Stolz, C. Weinzapfel, and J. Kimmons, Proc. SPIE 4347, 109 (2001).

15. R. A. Negres, C. W. Carr, I. L. Bass, D. A. Alessi, T. A. Laurence, K. Stanion, G. Guss, D. A. Cross, P. J. Wegner, and C. J. Stolz, Proc. SPIE 9632, 963206 (2015).

16. "Lasers and laser-related equipment: test methods for laser-induced damage threshold," ISO Standard Nos. 21254-1-21254-4 (2011).

17. M. Sozet, J. Neauport, E. Lavastre, N. Roquin, L. Gallais, and L. Lamaignère, Opt. Lett. 41, 804 (2016).

18. ImageJ software, http://imagej.nih.gov/ij/.

19. S. R. Qiu, J. E. Wolfe, A. M. Monterrosa, M. D. Feit, T. V. Pistor, and C. J. Stolz, Appl. Opt. 50, 9 (2011).

20. G. Razé, J.-M. Morchain, M. Loiseau, L. Lamaignère, M. Josse, and H. Bercegol, Proc. SPIE 5647, 197 (2005).

21. C. J. Stolz, J. E. Wolfe, J. J. Adams, M. G. Menor, N. E. Teslich, P. B. Mirkarimi, J. A. Folta, R. Soufli, C. S. Menoni, and D. Patel, Appl. Opt. 53, A291 (2014). 